\title{
Les relations de couple dans la littérature maghrébine francophone : entre affirmation de soi et désir de liberté
}

\section{El hadji CAMARA, Université Brock}

La littérature francophone maghrébine contemporaine se caractérise par la richesse des thématiques abordées mais également par la place de plus en plus grande qu'occupent les femmes dans ce champ, que ce soit en tant qu'écrivaines que comme personnages principaux des œuvres fictionnelles. De Kateb Yacine à Malika Mokeddem, en passant par Rachid Boudjedra, Assia Djebar et Tahar Ben Jelloun, les écrivains maghrébins se sont emparés de sujets aussi divers que les conflits entre tradition et modernité, l'exil, l'immigration et la condition féminine. La romancière algérienne Mokeddem dont les œuvres sont analysées dans ce dossier par Simona Pruteau ne fait pas exception à cette prise de parole, symbole de liberté retrouvée et assumée. Il s'y ajoute la voix du romancier marocain Ben Jelloun, telle que révélée par les articles de Ramona Mielusel et de Florina Matu, qui s'érige en chantre du féminisme dans sa pratique esthétique et discursive.

En effet, l'œuvre de Mokaddem est à la fois un réquisitoire contre la société patriarcale perpétuant des pratiques culturelles et coutumières rétrogrades et une ode aux femmes maghrébines qui, au fil du temps, ont appris à s'assumer et à assurer leur indépendance financière vis-à-vis des hommes. Pruteau, qui retrace l'évolution des personnages féminins chez l'écrivaine, signale dans son analyse une profonde mutation chez ceux-ci depuis la parution de Les Hommes qui marchent en 1990. Elle met notamment en relief dans son article les relations conflictuelles dans la famille, la place peu enviable réservée à la conjointe dans le couple et le désir de liberté manifeste qu'expriment toutes celles qui étaient privées de parole en public dans la société.

Ainsi, l'auteure expose dans un premier temps les motifs qui permettaient de soumettre la femme à la domination de l'homme. Elle indique que, chez les personnages de Mokaddem, si la famille est présentée de prime abord comme une assurance et une garante du bonheur conjugal dans la société traditionnelle, elle se révèle en fin de compte comme un facteur de répression et de privation des libertés pour les femmes, au profit exclusif des hommes. Mais les personnages 
féminins qui étaient résignés, car vivant au dépendant du père, du frère ou du mari, ont tout à coup brisé les carcans qui les étouffaient grâce à l'éducation et à travers une indépendance financière. Soulignant de ce fait le rôle prépondérant de l'instruction et de l'argent dans la conquête des libertés individuelles chez les femmes du Maghreb, Pruteau montre avec pertinence que, de Yamina à Shamsa, le chemin parcouru a été long et difficile, mais que désormais les personnages féminins de Mokaddem ont atteint une grande maturité et peuvent être présentés en modèles pour toutes les femmes maghrébines.

Mielusel, pour sa part, examine l'évolution du statut de la femme marocaine en montrant comment, de génération en génération et à travers toutes les couches sociales, le rôle joué par les femmes elles-mêmes dans leur émancipation s'est accru considérablement. Elle montre que la forme nouvelle du code du statut personnel marocain ou la Moudawana, promulguée par le Roi Mohamed VI en 2004, qui accorde plus de droits aux femmes, est le résultat de ce long combat des Marocaines pour s'émanciper et acquérir plus de liberté. A travers l'analyse comparée de deux œuvres, Mielusel montre que, malgré les trente années d'écart entre leurs dates de publication, La Civilisation, ma mère (1972) de Driss Chraïbi et Amour sorcier (2004) de Ben Jelloun se rejoignent dans la mise en scène de ce parcours émancipateur qui transparait dans les œuvres littéraires du royaume chérifien de manière générale, afin d'arracher la femme de l'influence des pièces maitresse du système patriarcal, tel que le père, le frère ou le mari.

Évoquant le dialogue intergénérationnel, aussi bien dans le champ social que dans le champ littéraire, l'analyse de Mielusel révèle avec justesse que les questions comme l'humiliation de la femme, les violences conjugales et le thème de la filiation, entre autres, ont été et demeurent toujours des sujets de prédilection pour les écrivains marocains de toutes les générations tant soit peu soucieux de la condition féminine. Le personnage de la mère dans $L a$ Civilisation, ma mère est le symbole de cette transmission intergénérationnelle, source de liberté et de changement progressif du statut social, juridique et politique de la femme au Maroc. Et à ce titre, la coexistence du monde de la tradition et de la modernité chez Ben Jelloun et la transformation par l'éducation du personnage de la mère chez Chraïbi signifient en quelque sorte la fin de l'isolement dans le combat et de la solitude intérieure de la femme marocaine qui s'était toujours repliée sur elle-même dans le passé. L'exemple de Najat dans Amour sorcier, femme éduquée, émancipée, sûre d'elle-même et en parfait contrôle de sa situation de couple, augure le 
type de femme qui émerge dans la société marocaine, même au prix d'une lutte continue et de tous les instants.

La vie de couple et ses péripéties constituent également la trame de l'analyse de Matu. S'appuyant sur Le bonheur conjugal (2012) de Ben Jelloun qui met l'accent sur l'effritement des liens de mariage sous les effets conjugués des coutumes de la société traditionnelle avec comme principaux agents la belle-famille et les parents, Matu montre comment l'écrivain marocain plonge le lecteur au cœur d'un conflit aux multiples relents. Entre un mari cynique et avare et une épouse résignée mais revancharde, l'œuvre analysée ici illustre à bien des égards les contradictions d'un mariage contracté sur un malentendu entre des conjoints qui n'avaient ni la même conception du foyer conjugal ni les mêmes attentes pour atteindre le bonheur d'une vie commune.

Les tensions nées au sein du couple sont les reflets de ce malentendu originel et de la différence de classe entre le mari et son épouse, mais également entre leurs familles respectives. Alors que le mari, issu d'une famille riche et conservatrice, accorde une grande importance à l'argent, au bien-être social et aux mondanités, l'épouse traîne toujours les stigmates de ses origines subalternes. Moquée par sa belle-famille et délaissée par son époux, elle finit par lui en vouloir au point de souhaiter sa ruine. Quant au mari, il regrette d'avoir épousé celle qu'il a pourtant toujours considérée comme étant la plus belle femme du monde.

Mais, pour Ben Jelloun, cette crise du couple est en fait la traduction de la crise économique et sociale, donc une crise globale et beaucoup plus profonde que traverse la société marocaine. L'analyse de Matu permet de révéler avec exactitude l'ampleur de cette crise sociétale qui se manifeste dans Le bonheur conjugal à travers le couple, en mettant l'accent sur le manque de raison, l'entêtement et l'aveuglement général qui s'emparent des sociétés contemporaines. Dans ce chaos, la puissance de l'argent, qui détruit tout sur son passage, est clairement soulignée dans l'analyse de Matu, laquelle expose en même temps que l'écroulement du bonheur conjugal est du fait de tous les conjoints, rongés par la haine et par le désir de vengeance inassouvi.

La lecture des articles de ce dossier permettra de mesurer le chemin parcouru par les femmes, qu'elles soient mères, épouses ou sœurs, dans la conquête de leur liberté et dans l'évolution de leur statut dans la société maghrébine. Car en prenant la parole et en se rendant 
moins dépendantes des hommes, elles ont renversé les rapports de force dans les relations de couple et se sont libérées de certains paramètres socioculturels autoritaires. 